\title{
Ultrasonography of Median Nerve and Electrophysiologic Severity in Carpal Tunnel Syndrome
}

\author{
Seok Kang, M.D., Hee Kyu Kwon, M.D. ${ }^{1}$, Ki Hoon Kim, M.D. ${ }^{2}$, Hyung Seok Yun, M.D.
}

\begin{abstract}
Department of Physical Medicine and Rehabilitation, Gangwon-do Rehabilitation Hospital, Chuncheon 200-853,
\end{abstract}
${ }^{1}$ Korea University College of Medicine, Seoul 136-705, ${ }^{2}$ SahmYook Medical Center, Seoul 130-711, Korea

Objective To investigate the correlation of the ultrasonographic wrist-to-forearm median nerve area ratio (WFR) and cross sectional area of median nerve at the wrist (CSA-W) to the electrophysiologic severity in patients with carpal tunnel syndrome (CTS).

Method One hundred and ten wrists electrophysiologically graded as mild, moderate, and severe CTS and 38 healthy controls underwent ultrasonography of median nerve at the distal wrist crease and mid-forearm. WFR and CSA-W were analyzed according to the severity of CTS.

Results WFR was $1.12 \pm 0.14,1.91 \pm 0.33,2.27 \pm 0.47$ and $3.02 \pm 0.97$ and the CSAs-W was $7.23 \pm 1.67 \mathrm{~mm}^{2}, 13.51 \pm 3.72$ $\mathrm{mm}^{2}, 14.67 \pm 2.93 \mathrm{~mm}^{2}$, and $18.74 \pm 6.01 \mathrm{~mm}^{2}$ in controls, mild $(\mathrm{n}=28)$, moderate $(\mathrm{n}=46)$, and severe $(\mathrm{n}=36)$ CTS, respectively. CSA-W displayed significant differences between the control and the mild CTS, moderate CTS and severe CTS groups. However, there was no significant difference between mild CTS and moderate CTS groups. WFR revealed significant difference between all groups. The sensitivity and specificity of the WFR in grading the severity of CTS were higher than those of the CSA-W.

Conclusion Ultrasonography is a useful complementary tool for the evaluation of CTS. Both WFR and CSA-W are highly correlated with severity grade of CTS. However, WFR is superior to CSA-W for diagnosis and grading of the severity of CTS.

Key Words Carpal tunnel syndrome, Ultrasonography, Electrophysiologic severity, Cross sectional area, Ratio

Received July 23, 2011; Accepted October 8, 2011

Corresponding author: Hee Kyu Kwon

Department of Rehabilitation Medicine, Korea University College of Medicine, 126-1, Anam-dong 5ga, Sungbuk-gu, Seoul 136-705, Korea Tel: +82-2-920-6480, Fax: +82-2-920-9951, E-mail: hkkwon@korea.ac.kr (c) This is an open-access article distributed under the terms of the Creative Commons Attribution Non-Commercial License (http:// creativecommons.org/licenses/by-nc/3.0) which permits unrestricted noncommercial use, distribution, and reproduction in any medium, provided the original work is properly cited.

Copyright (c) 2012 by Korean Academy of Rehabilitation Medicine

\section{INTRODUCTION}

Carpal tunnel syndrome (CTS) is the most common entrapment peripheral neuropathy, which can be diagnosed by history taking, physical examinations and electrodiagnosis. Electrodiagnosis is most valuable in the diagnosis of CTS and the evaluation of its severity, ${ }^{1}$ but is considered to be a bit invasive. On the other hand, high-resolution ultrasonography provides a simple, noninvasive means of visualizing peripheral nerves and the surrounding anatomic structures. In particular, it has 
been known to be useful in the evaluation of entrapment neuropathies such as CTS, and its use has increased. ${ }^{2-5}$

In the case of CTS patients, local swelling of the median nerve is observed proximal to the carpal tunnel. ${ }^{6}$ In this regard, many researchers have presented the cross sectional area of the median nerve, measured at the distal wrist (CSA-W), as an index for the ultrasonographic diagnosis of CTS. ${ }^{2,3,7}$ However, the values of the CSA-W have varied among reports, being $7-9.5 \mathrm{~mm}^{2}$ in the normal and 9-15 $\mathrm{mm}^{2}$ in patients with CTS. ${ }^{7,8}$ This variability might be due to a technical problem in the ultrasonographic measurement and the differences between populations studied. The cross sectional area (CSA) of a nerve may increase in proportion to body weight ${ }^{9,10}$ and also could be affected by certain diseases such as demyelinating hereditary motor sensory neuropathy, in which the CSA of the whole nerve increases. ${ }^{11}$ Therefore, the CSA-W could result in false positive diagnosis of CTS. ${ }^{12}$

A recent study reported that the CSA of normal median nerve was the same at the wrist and in the forearm. ${ }^{13}$ Based on this finding, a ratio between the median nerve area at the wrist and that in the forearm (WFR) is suggested as an alternative diagnostic index. ${ }^{14}$

It is crucial to classify the severities and neurophysiologic types of CTS, in treatment planning and followup. Many researchers have classified CTS severities with clinical patterns and electrophysiological findings. ${ }^{15-20}$ Recently, it was suggested that the CSA-W can be a useful index for ultrasonography-based classification of CTS severity. ${ }^{21}$ However, CSA-W have been measured only recently. The WFR is expected to be more helpful to classify CTS severities.

In this study, we compared WFR and CSA-W according to the electrophysiologic severity in patients with CTS and in healthy controls to evaluate whether WFR is useful in diagnosing and grading the severity of CTS.

\section{MATERIALS AND METHODS}

\section{Subjects}

This study was conducted on a group of patients having the clinical symptoms of CTS such as hand tingling, pain, burning sensation, dysesthesia, grip weakness and thenar atrophy in their 110 hands and meeting electrodiagnostic criteria, as well as on a control group composed of healthy people with their 38 hands. Patients with systemic peripheral neuropathies such as diabetic neuropathy, neuropathies other than CTS or radiculopathy were excluded. The study group was composed of 100 female hands and 10 male hands, and the control group was composed of 36 female hands and two male hands. The patients in the case group were classified into three subgroups as to CTS severity graded by electrodiagnosis (i.e., mild, moderate and severe groups; 28 hands, 46 hands and 36 hands, respectively) (Table 1). The average age of the case group was 53.18. The ages of subgroups averaged $56.29,56.87$ and 57.61 years, respectively. The subgroups did not show significant differences in age, sex ratio and the ratio of left hands to right hands (left-right ratio) (Table 1).

This study was conducted with the approval of the relevant institutional review board and the consent of patients.

\section{Methods}

Electrodiagnosis: Electrodiagnosis was performed by using a Counter Point MK2 machine (Dantek, Copenhagen, Denmark). The temperature of each hand was maintained at $\geq 32^{\circ} \mathrm{C}$. The median motor response was recorded over the abductor pollicis brevis muscle with median nerve stimulation $8 \mathrm{~cm}$ proximal to the active recording electrode. The onset latency and baseline to peak amplitude were measured. The median sensory response was recorded antidromically with a bar electrode over

Table 1. Baseline Characteristics of the Subjects

\begin{tabular}{lcccc}
\multicolumn{1}{c}{ Variable } & Control & Mild CTS & Moderate CTS & Severe CTS \\
\hline Number & 38 & 28 & 46 & 36 \\
Sex (female : male) & $36: 2$ & $26: 2$ & $42: 4$ & $32: 4$ \\
Side (right : left) & $18: 20$ & $16: 12$ & $23: 23$ & $17: 19$ \\
Age (years) & $53.18 \pm 6.20$ & $56.29 \pm 9.70$ & $56.87 \pm 8.61$ & $57.61 \pm 9.58$ \\
Duration of symptom (months) & & $24.61 \pm 31.27$ & $29.68 \pm 31.84$ & $20.03 \pm 29.74$ \\
\hline
\end{tabular}

CTS: Carpal tunnel syndrome 
Table 2. Severity of Carpal Tunnel Syndrome

\begin{tabular}{|c|c|c|c|}
\hline Severity & Sensory NCS* & Motor NCS $^{\dagger}$ & APB Needle EMG \\
\hline $\begin{array}{l}\text { Mild } \\
\text { At least three of the } \\
\text { following Sensory } \\
\text { and motor nerve } \\
\text { conduction }\end{array}$ & $\begin{array}{l}\text { 1. } 14 \mathrm{~cm} \text { wrist stimulation, peak latency }>3.7 \mathrm{~ms} \\
\text { 2. } 14 \mathrm{~cm} \text { wrist stimulation, the peak latency: } \\
\text { proximal } 7 \mathrm{~cm}>\text { distal } 7 \mathrm{~cm} \\
\text { 3. Transcarpal } 5 \mathrm{~cm} \text { short-segment latency: onset } \\
\text { latency }>1.3 \mathrm{~ms} \text {, peak latency }>1.5 \mathrm{~ms} \\
\text { 4. } 14 \mathrm{~cm} \text { SNAP amplitude: } 16-20 \mathrm{uV} \\
\text { 5. Conduction block greater than } 50 \% \text { in wrist } \\
\text { palm stimulation if } 14 \mathrm{~cm} \text { stimulation amplitude } \\
\geq 20 \mathrm{uV}\end{array}$ & $\begin{array}{l}\text { 6. Distal latency } \\
\text { >4.2 ms. } \\
\text { 7. CMAP amplitude: } \\
\text { 4.1-4.5 mV } \\
\end{array}$ & Normal \\
\hline $\begin{array}{l}\text { Moderate } \\
\text { Mild PLUS at least } \\
\text { two of the following: }\end{array}$ & $\begin{array}{l}\text { 1. Wrist stimulation }(14 \mathrm{~cm}) \text { SNAP amplitude } 6 \text { - } 15 \\
\mathrm{uV} \\
\text { 2. Conduction block greater than } 50 \% \text { at wrist \& } \\
\text { palm stim. If SNAP } \geq 10 \mathrm{uV} \text { with } 14 \mathrm{~cm} \text { wrist } \\
\text { stimulation }\end{array}$ & $\begin{array}{l}\text { 3. CMAP amplitude } \\
2.1-4 \mathrm{mV}\end{array}$ & $\begin{array}{l}\text { 4. Fibrillation }( \pm) \\
\text { 5. Abnormal MUAP } \\
\text { with intermediate } \\
\text { interference pattern }\end{array}$ \\
\hline $\begin{array}{l}\text { Severe } \\
\text { Moderate PLUS: }\end{array}$ & 1. SNAP amplitude $\leq 5 \mathrm{uV}$ & $\begin{array}{l}\text { 2. CMAP amplitude } \\
\leq 2 \mathrm{mV}\end{array}$ & $\begin{array}{l}\text { 3. Fibrillation }(+) \\
\text { 4. Abnormal MUAP } \\
\text { with discrete } \\
\text { activity or single } \\
\text { unit pattern }\end{array}$ \\
\hline
\end{tabular}

NCS: Nerve conduction study, APB: Abductor pollicis brevis, EMG: Electromyography, CMAP: Compound muscle action potential, SNAP: Sensory nerve action potential, MUAP: Motor unit action potential

${ }^{*}$ Median nerve sensory conduction study with Ill digit recording recording and antidromic stimulation, ${ }^{\dagger}$ Median nerve motor conduction study with abductor pollicis brevis (APB) muscle recording and $8 \mathrm{~cm}$ proximal stimulation at wrist, ${ }^{\ddagger}$ Motor CTS: Abnormal nerve conduction limited to only distal median motor nerve (wrist stimulation-APB recording)

the third digit and median nerve stimulation given at two points, $7 \mathrm{~cm}$ proximal to the recording electrode in the palm and $14 \mathrm{~cm}$ proximally at the wrist. To test the $5 \mathrm{~cm}$ transcarpal segment, the median nerve was stimulated at two points: the distal wrist crease and $5 \mathrm{~cm}$ distal to the distal wrist crease in the palm. The onset and peak latencies and baseline to peak amplitude were measured and the onset latency difference of $5 \mathrm{~cm}$ transcarpal segment was calculated. Needle electromyography (EMG) was performed on the abductor pollicis brevis muscle. CTS severity was classified according to Steven's classification and in accordance with the criteria of the electrodiagnosis laboratory at Korea University Anam hospital (Table 2)..$^{19,22,23}$

Ultrasonography: Ultrasonography was performed by use of M2540A Envisor Diagnostic Ultrasound Imaging System (Philips, Bothell, USA). The transducer was always kept perpendicular to the median nerve to avert anisotropy. No additional force was applied other than the weight of the probe and the wrist was kept in the neutral position to avoid causing any artificial nerve deformity. The median nerve was imaged in an axial plane at

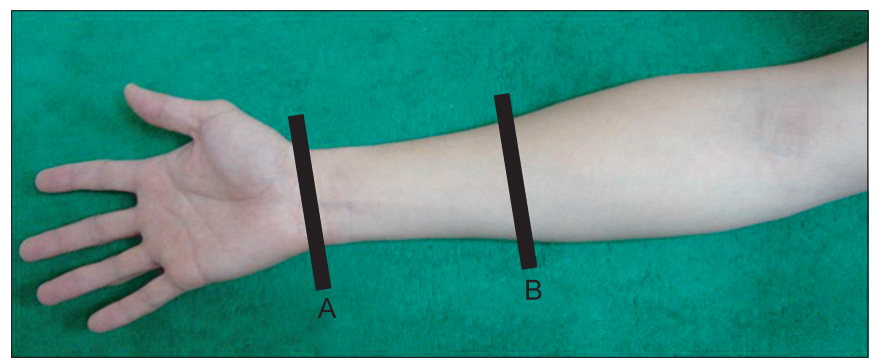

Fig. 1. Placement of ultrasonographic probe at the forearm. Ultrasonographic transverse scan was done at two different levels. The cross sectional areas of median nerve were measured at the distal wrist crease (A) and $12 \mathrm{~cm}$ proximal to this level (B). A/B ratio was obtained.

the distal wrist crease and $12 \mathrm{~cm}$ proximal in the forearm (Fig. 1). CSA measurements were performed at the inner border of the thin hyperechoic epineural rim by the continuous tracing technique and the average values were calculated after serially measuring three times. WFR was calculated with the values of CSA measured at the distal wrist crease and $12 \mathrm{~cm}$ proximal in the forearm (Fig. 2).

Statistical analyses: Statistical analyses were per- 

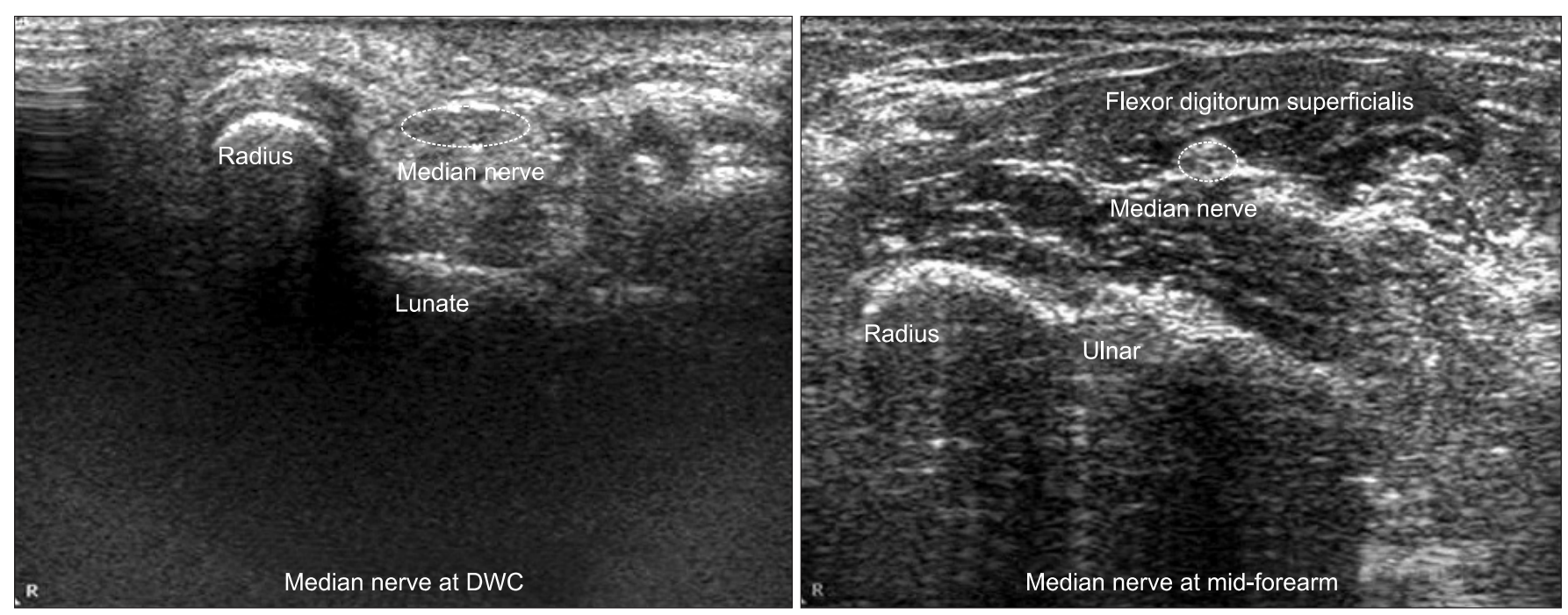

Fig. 2. Median nerve images. The nerve is identified by its location and characteristic stippled appearance. DWC: Distal wrist crease.

Table 3. Spearman's Correlation Coeffiency of the Ultrasonographic Measurements and Severity of Carpal Tunnel Syndrome

\begin{tabular}{lccc}
\hline & $\begin{array}{c}\text { Severity of } \\
\text { CTS }\end{array}$ & CSA at wrist & WFR \\
\hline Severity of CTS & - & $0.728^{*}$ & $0.808^{*}$ \\
CSA at wrist & $0.728^{*}$ & - & $0.834^{*}$ \\
WFR & $0.808^{*}$ & $0.834^{*}$ & - \\
\hline
\end{tabular}

CTS: Carpal tunnel syndrome, CSA: Cross sectional area, WFR: Wrist-to-forearm ratio ${ }^{*} \mathrm{p}<0.05$

formed by using SPSS, version 18.0 (SPSS, Cary, USA). Data are reported as mean \pm standard deviations. The Kruskal-Wallis test was used to evaluate differences in the ages, symptom durations and ultrasonographic values between the groups. The Mann-Whitney U test with Bonferroni correction was used as post-hoc test to analyze differences in the ultrasonographic values according to the electrodiagnostic severity grades. The chi-square test was used to assess the other basic characteristics of each groups. The Spearman correlation analysis was performed to examine the correlation between ultrasonographic values and electrodiagnostic severities. The statistical significance was set at $\mathrm{p}<0.05$. Bonferroni correction was made for six comparisons; thus, the $\mathrm{p}$-value for significance was $<0.05 / 6=0.0083$. Receiver operating characteristic (ROC) curves were used to detect optimal possible cut-off values of the ultrasonographic data ac- cording to electrodiagnostic severities, and specificity and sensitivity were obtained.

\section{RESULTS}

On the correlation analysis between ultrasonographic values and electrodiagnostic severities, significant correlations were observed in the CSA-W $(r=0.728)$ as well as in the WFR ( $\mathrm{r}=0.808)$. WFR showed a higher correlation (Table 3). The CSA-W had the value of $7.23 \mathrm{~mm}^{2}, 13.51$ $\mathrm{mm}^{2}, 14.61 \mathrm{~mm}^{2}$ and $18.74 \mathrm{~mm}^{2}$ in the control group, mild group, moderate group and severe group, respectively, showing significant differences. CSA of the median nerve, measured at $12 \mathrm{~cm}$ proximal to the wrist crease, was $6.88 \mathrm{~mm}^{2}, 7.14 \mathrm{~mm}^{2}, 6.57 \mathrm{~mm}^{2}$ and $6.39 \mathrm{~mm}^{2}$ in the control group, mild group, moderate group and severe group, respectively, showing no significant differences. The wrist-forearm ratio was 1.12, 1.91, 2.27 and 3.02 in the four groups (same respective order) and showed significant differences (Table 4).

Post-hoc analysis using Mann-Whitney U test with Bonferroni correction showed that in relation to the CSA-W, there were significant differences between the control group and the mild group, and between the moderate group and the severe group. However, there was no significant difference between the mild group and the moderate group. With WFR, there were significant differences between the control group and the mild group, between the mild group and the moderate group and between the 
moderate group and the severe group (Table 4).

The ultrasonographic cut-off values for the diagnosis of CTS were obtained by use of the ROC curve. Likewise, the cut-off values, suitable for the diagnosis of moderate to severe and severe CTS, were obtained in the same way (Fig. 3). The areas under the ROC curve of the CSA-W in diagnosis of CTS, moderate to severe CTS and severe CTS were $0.988,0.862$ and 0.804 , respectively $(\mathrm{p}<0.05)$. In the case of WFR, the values were $0.999,0.912$ and 0.859 , respectively $(\mathrm{p}<0.05)$; thus, the areas under the ROC curve showed higher values in the latter. The cut-off value of the CSA-W, obtained by the ROC curve, indicated $9.5 \mathrm{~mm}^{2}$, $12.05 \mathrm{~mm}^{2}$ and $14.15 \mathrm{~mm}^{2}$ in diagnosis of CTS, moderate to severe CTS and severe CTS, respectively. Meanwhile, the cut-off value of the WFR indicated 1.34, 1.89 and 2.2, respectively. The sensitivity and specificity of the cut-off value was superior in the WFR (Table 5).

Table 4. Ultrasonographic Measures of the Subjects

\begin{tabular}{llccc}
\hline & Control & Mild CTS & Moderate CTS & Severe CTS \\
\hline CSA at wrist $\left(\mathrm{mm}^{2}\right)^{*}$ & $7.23 \pm 1.63^{\ddagger, \S, \|}$ & $13.51 \pm 3.72^{\dagger, \|}$ & $14.67 \pm 2.93^{\dagger, \|}$ & $18.74 \pm 6.01^{\dagger, \neq, \S}$ \\
CSA at forearm $\left(\mathrm{mm}^{2}\right)$ & $6.88 \pm 1.95$ & $7.14 \pm 1.76$ & $6.57 \pm 1.27$ & $6.39 \pm 1.46$ \\
WFR $^{*}$ & $1.12 \pm 0.14^{\ddagger, \S, \|}$ & $1.91 \pm 0.33^{\dagger, \S, \|}$ & $2.27 \pm 0.47^{\dagger, \uparrow, \|}$ & $3.02 \pm 0.97^{\dagger,+, \S}$ \\
\hline
\end{tabular}

CTS: Carpal tunnel syndrome, CSA: Cross sectional area, WFR: Wrist-to-forearm ratio

${ }^{*} \mathrm{p}<0.05$, ${ }^{\dagger}$ Significant difference from control group $(\mathrm{p}<0.0083)$, ${ }^{\dagger}$ Significant difference from mild CTS group ( $\left.\mathrm{p}<0.0083\right)$,

${ }^{\S}$ Significant difference from moderate CTS group ( $\left.\mathrm{p}<0.0083\right)$, "Significant difference from severe CTS group ( $\mathrm{p}<0.0083$ )

(A)

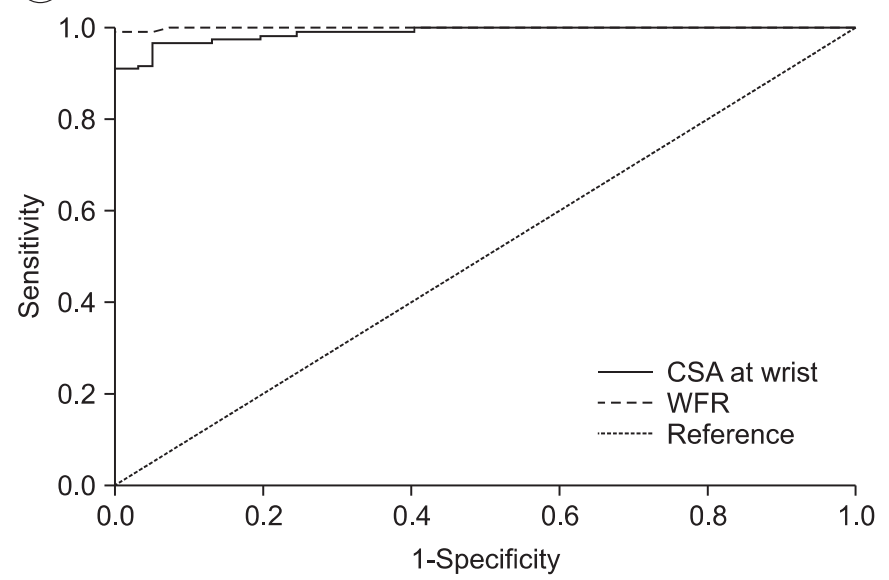

(C)

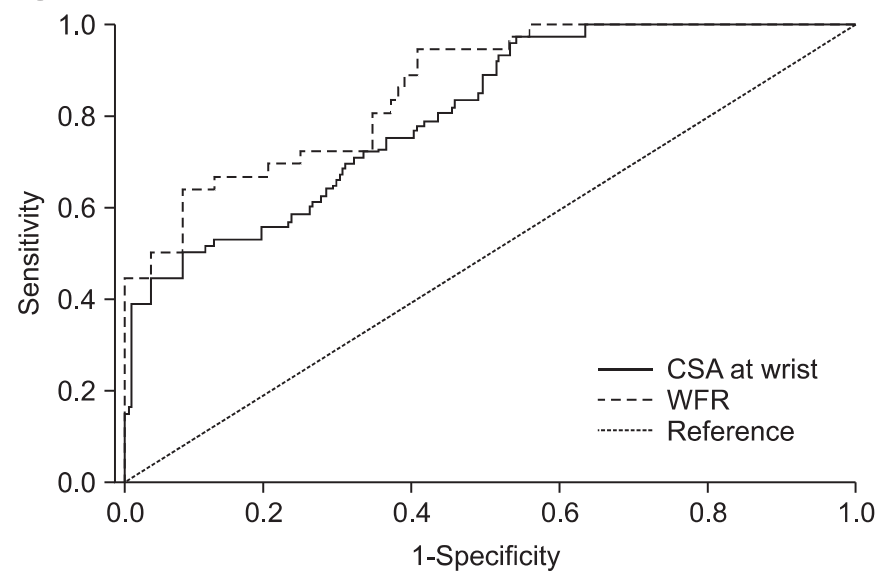

(B)

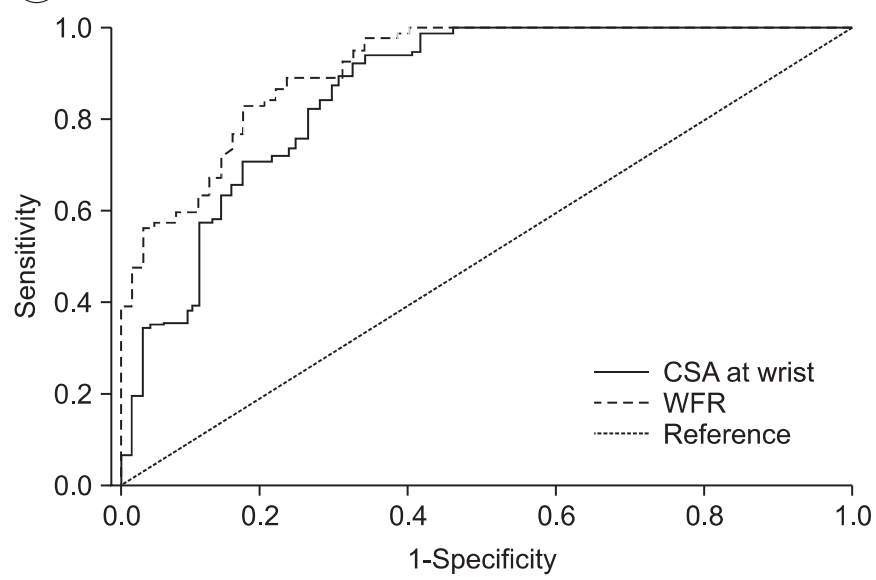

Fig. 3. A receiver operator characteristic (ROC) curve showing the relationship between sensitivity and specificity for each ultrasonographic parameter in diagnosis of carpal tunnel syndrome (A), moderate to severe carpal tunnel syndrome (B), and severe carpal tunnel syndrome (C). CSA: Cross sectional area, WFR: Wrist-to-forearm ratio. 
Table 5. Sensitivity and Specificity of Optimal Cut-Off Values that Discriminate the Different Grades of CTS Severity as Detected by Ultrasonography

\begin{tabular}{lcccccccc}
\hline \multirow{2}{*}{ Electrodiagnosis } & \multicolumn{2}{c}{ Cut-off value } & & \multicolumn{2}{c}{ Sensitivity (\%) } & & \multicolumn{2}{c}{ Specificity (\%) } \\
\cline { 2 - 3 } \cline { 7 - 8 } & $\begin{array}{c}\text { CSA at wrist } \\
\left(\mathbf{m m}^{\mathbf{2}}\right)\end{array}$ & WFR & & CSA at wrist & WFR & & CSA at wrist & WFR \\
\hline CTS & 9.5 & 1.34 & & 96.4 & 99.9 & 92.1 & 100 \\
Moderate to Severe CTS & 12.05 & 1.89 & & 82.9 & 82.9 & & 82.7 & 83.3 \\
Severe CTS & 14.15 & 2.2 & 69.4 & 72.2 & 68.7 & 72.3 \\
\hline
\end{tabular}

CSA: Cross sectional area, WFR: Wrist-to-forearm ratio, CTS: Carpal tunnel syndrome

\section{DISCUSSION}

CTS is usually diagnosed by clinical evaluation and electrodiagnosis, and the therapeutic plan is decided on its severity. In this regard, various scales have been developed. In recent times, ultrasonography emerged as a promising diagnostic tool for entrapment neuropathies, particularly CTS. In the case of CTS, local swelling of the median nerve is observed at the proximal carpal tunnel on ultrasonography, and CSA-W is useful to diagnose CTS and is highly correlated with clinical symptoms. ${ }^{24,25}$ However, the CSA-W may vary depending upon the measurer or depending upon whether the epineurium is included in the measurement. Several studies reported that body weight correlates with CSA-W. ${ }^{9,10}$ In this connection, it has been suggested that WFR could be a new index for the diagnosis of CTS. ${ }^{14}$

Grading the severity of CTS is important in treatment planning and in follow-up. Some researchers have studied the correlation of ultrasonographic findings and CTS severities. Lee et al ${ }^{26}$ reported that the swelling of the median nerve at the proximal carpal tunnel was related to the results of nerve conduction study. Bayrak et al. ${ }^{27}$ reported that the motor unit number estimation of the abductor pollicis brevis muscle was negatively correlated with CSA of the median nerve at the proximal and middle segment of carpal tunnel. Padua et al. ${ }^{28}$ reported that a positive correlation exists between CSA-W and the neurophysiological severity of CTS. In this connection, El Miedany et al. analyzed the correlation between electrodiagnostic severity and the CSA-W and suggested cutoff points that discriminate between different grades of CTS severity as $10.0-13.0 \mathrm{~mm}^{2}$ for mild patients, $13.0-15.0$ $\mathrm{mm}^{2}$ for moderate patients and $>15.0 \mathrm{~mm}^{2}$ for severe patients. ${ }^{21}$ However, the false positive rate is more likely to increase if CTS is diagnosed only by the CSA-W.
In this study, we compared electrodiagnostic CTS severities and ultrasonographic values. CSA-W increased according to CTS severity. However, mild CTS and moderate CTS did not show significant differences in CSA-W. WFR was more highly related to CTS severity than CSA$\mathrm{W}$, and significant differences were observed between all groups. The sensitivity and specificity, obtained by the ROC curve, were superior in WFR.

In common with this study, some previous studies reported increased CSA-W according to CTS severity. ${ }^{21,26-28}$ However, Asians are different from Westerners in CSA$\mathrm{W} 12,{ }^{29}$ and also the values may vary depending upon the measurer. Moreover, there has been controversy about the correlation between body weight and CSA-W. ${ }^{9,10}$ WFR may be advantageous to grade severity of CTS, inasmuch as it is possible to reduce the differences amongst researchers ${ }^{14}$ and to correct the differences caused by somatotype or race.

Due to the absence of somatotype information, this study could not analyze the correlation between body weight or height and CSA-W. Moreover, patients' clinical symptoms could not be reflected in the classification of CTS severities. In addition, the control group and the patient groups were composed of comparatively small numbers. Furthermore, the results were obtained on the basis of nonparametric statistics because data could not meet the normality. As a result, in the CSA-W and WFR determinations, the standard deviation increased in proportion to the CTS severity, and, thus, sensitivity and specificity became relatively lower. Alternatively, it might have been because electrophysiological severities were not consistent with anatomical findings. Large-scale studies are required. 


\section{CONCLUSION}

In addition to clinical symptoms and electrodiagnosis, ultrasonography may be complementary to the diagnosis of CTS and the classification of its severities. In this study, CSA-W increased in proportion to the severity of CTS. However, WFR displayed statistical significance in relation to the assessment of each severity. Moreover, the cut-off value of each severity showed higher sensitivity and specificity. Altogether, WFR is amore accurate index than CSA-W.

\section{REFERENCES}

1. Jablecki CK, Andary MT, Floeter MK, Miller RG, Qartly CA, Vennix MJ, Wilson JR. Practice parameter: electrodiagnostic studies in carpal tunnel syndrome. Report of the American Association of Electrodiagnostic Medicine, American Academy of Neurology, and the American Academy of Physical Medicine and Rehabilitation. Neurology 2002; 58: 1589-1592

2. Buchberger W, Schon G, Strasser K, Jungwirth W. High-resolution ultrasonography of the carpal tunnel. J Ultrasound Med 1991; 10: 531-537

3. Wong SM, Griffith JF, Hui AC, Lo SK, Fu M, Wong KS. Carpal tunnel syndrome: diagnostic usefulness of sonography. Radiology 2004; 232: 93-99

4. Yoon JS, Kim BJ, Kim SJ, Kim JM, Sim KH, Hong SJ, Walker FO, Cartwright MS. Ultrasonographic measurements in cubital tunnel syndrome. Muscle Nerve 2007; 36: 853-855

5. Yoon JS, Walker FO, Cartwright MS. Ultrasonographic swelling ratio in the diagnosis of ulnar neuropathy at the elbow. Muscle Nerve 2008; 38: 1231-1235

6. Tuncali D, Barutcu AY, Terzioglu A, Aslan G. Carpal tunnel syndrome: comparison of intraoperative structural changes with clinical and electrodiagnostic severity. Br J Plast Surg 2005; 58: 1136-1142

7. Hammer HB, Hovden IA, Haavardsholm EA, Kvien TK. Ultrasonography shows increased cross-sectional area of the median nerve in patients with arthritis and carpal tunnel syndrome. Rheumatology (Oxford) 2006; 45: 584-588

8. Beekman R, Visser LH. Sonography in the diagnosis of carpal tunnel syndrome: a critical review of the literature. Muscle Nerve 2003; 27: 26-33
9. Peeters EY, Nieboer KH, Osteaux MM. Sonography of the normal ulnar nerve at Guyon's canal and of the common peroneal nerve dorsal to the fibular head. J Clin Ultrasound 2004; 32: 375-380

10. Cartwright MS, Shin HW, Passmore LV, Walker FO. Ultrasonographic findings of the normal ulnar nerve in adults. Arch Phys Med Rehabil 2007; 88: 394-396

11. Martinoli C, Schenone A, Bianchi S, Mandich P, Caponetto C, Abbruzzese M, Derchi LE. Sonography of the median nerve in Charcot-Marie-Tooth disease. AJR Am J Roentgenol 2002; 178: 1553-1556

12. Cho JM, Yoon JS, Kim SJ, Park BK, Lee GH, Jeong JS. Feasibility of ultrasonographic area ratio of median nerve in the diagnosis of carpal tunnel syndrome in Korea. J Korean Acad Rehab Med 2009; 33: 627-631

13. Cartwright MS, Shin HW, Walker FO. Ultrasonographic characteristics of the normal median nerve. Neurology 2006; 66 Suppl 2: A83

14. Hobson-Webb LD, Massey JM, Juel VC, Sanders DB. The ultrasonographic wrist-to-forearm median nerve area ratio in carpal tunnel syndrome. Clin Neurophysiol 2008; 119: 1353-1357

15. American Association of Electrodiagnostic Medicine. Guidelines in electrodiagnostic medicine. Practice parameter for electrodiagnostic studies in carpal tunnel syndrome. Muscle Nerve 1999; 22 Suppl 8: S141167

16. Bland JD. A neurophysiological grading scale for carpal tunnel syndrome. Muscle Nerve 2000; 23: 12801283

17. Giannini F, Cioni R, Mondelli M, Padua R, Gregori B, D'Amico P, Padua L. A new clinical scale of carpal tunnel syndrome: validation of the measurement and clinical-neurophysiological assessment. Clin Neurophysiol 2002; 113: 71-77

18. Padua L. A new approach to carpal tunnel syndrome: multicenter studies with multiperspective assessment. AAEM Course H; 2003 Sep 16-20; San Francisco, USA. Rochester: American Association of Electrodiagnostic Medicine; 2003

19. Stevens JC. AAEM minimonograph \#26: the electrodiagnosis of carpal tunnel syndrome. American Association of Electrodiagnostic Medicine. Muscle Nerve 1997; 20: 1477-1486

20. Wee AS. Carpal tunnel syndrome: a system for categorizing and grading electrophysiologic abnormalities. 
Electromyogr Clin Neurophysiol 2001; 41: 281-288

21. El Miedany YM, Aty SA, Ashour S. Ultrasonography versus nerve conduction study in patients with carpal tunnel syndrome: substantive or complementary tests? Rheumatology (Oxford) 2004; 43: 887-895

22. Lee HJ, Kwon HK. Electrophysiologic classification of severity of carpal tunnel syndrome. J Korean EMG Electrodiagn Med 2004; 6: 1-3

23. Cho YS, Lee SH, Kwon HK, Lee HJ. Reappraisal of nerve conduction studies in carpal tunnel syndrome. J Korean Acad Rehab Med 1998; 22: 861-865

24. Kotevoglu N, Gulbahce-Saglam S. Ultrasound imaging in the diagnosis of carpal tunnel syndrome and its relevance to clinical evaluation. Joint Bone Spine 2005; 72: 142-145

25. Buchberger W, Judmaier W, Birbamer G, Lener M, Schmidauer C. Carpal tunnel syndrome: diagnosis with high-resolution sonography. AJR Am J Roent- genol 1992; 159: 793-798

26. Lee CH, Kim TK, Yoon ES, Dhong ES. Correlation of high-resolution ultrasonographic findings with the clinical symptoms and electrodiagnostic data in carpal tunnel syndrome. Ann Plast Surg 2005; 54: 20-23

27. Bayrak IK, Bayrak AO, Tilki HE, Nural MS, Sunter T. Ultrasonography in carpal tunnel syndrome: comparison with electrophysiological stage and motor unit number estimate. Muscle Nerve 2007; 35: 344-348

28. Padua L, Pazzaglia C, Caliandro P, Granata G, Foschini M, Briani C, Martinoli C. Carpal tunnel syndrome: ultrasound, neurophysiology, clinical and patientoriented assessment. Clin Neurophysiol 2008; 119: 2064-2069

29. Park JY, Park SR, Lee SH, Choi KH. The ultrasonographic findings of the median nerve in the carpal tunnel according to age and sex of normal Korean adults. J Korean Acad Rehab Med 2008; 32: 564-569 